Research Article

\title{
Influence of Steel Fiber on Durability Performance of Concrete under Freeze-Thaw Cycles
}

\author{
Dong Li $(\mathbb{D}$, Qing Guo $(\mathbb{D}$, and Shi Liu \\ College of Civil Engineering, Liaoning Technical University, Fuxin 123000, China \\ Correspondence should be addressed to Shi Liu; liushi@lntu.edu.cn
}

Received 7 September 2021; Accepted 16 December 2021; Published 30 December 2021

Academic Editor: Tomasz Trzepieciński

Copyright (c) 2021 Dong Li et al. This is an open access article distributed under the Creative Commons Attribution License, which permits unrestricted use, distribution, and reproduction in any medium, provided the original work is properly cited.

\begin{abstract}
To verify the steel fiber effect on durability properties of the concrete in cold regions, four types of steel fiber reinforced concrete were prepared, and the fiber dosage were $0,20 \mathrm{~kg}, 40 \mathrm{~kg}$, and $60 \mathrm{~kg}$, respectively. The rapid freeze-thaw test was adopted to evaluate the frost resistance durability, and the evaluation indexes of the mass loss and the residual dynamic modulus of elasticity (RDME) the samples were compared, respectively. The frost damage of the matrix regarding the different freeze-thaw cycles (FTCs) was evaluated using the Weibull distribution. The capillary water absorption (CWA) experiments were also conducted corresponding to different freeze-thaw cycles (FTCs). The results revealed that the mass loss was not an effective index for frost damage evaluation of macro-steel fiber reinforced concrete. The FTCs corresponding to the loss of RDME to $60 \%$ were enhanced noticeably with the increase of fiber content. The relationship between the frost damage and the FTCs can be evaluated using the Weibull distribution. Compared with the PC, the frost resistance grade of the reinforced concrete with fiber dosage of $60 \mathrm{~kg} / \mathrm{m}^{3}$ increased by $125 \%$. After the frost action, the CWA capacity of concrete improved significantly, while, under the same FTCs, the CWA of the matrix decreased with the increment of macro-steel fiber dosage. The steel fiber showed a strong positive influence on enhancing the durability performance of concrete in cold region.
\end{abstract}

\section{Introduction}

The utilization of macrofibers to enhance various mechanical behavior of concrete is becoming more and more common [1]. Various influence parameters of fibers such as type, dosage, aspect ratio, and length have been investigated by the researchers [2-13]. Durability is one of the most critical aspects of the concrete, because it has a fundamental impact on the performance of the structures at serviceability stage. The fiber influence on durability performance of the concrete has been verified by some researchers [14-20]. The frost resistance of the matrix is one of the most important factors for durability of reinforced concrete structures in cold areas. Ma et al. [21] studied the frost resistance of the concrete with polypropylene fiber; the results revealed that the polypropylene fiber had a positive contribution to reducing the frost damage of the matrix. Li et al. [22] investigated the performance of reactive powder concrete reinforced by basalt fiber under freeze-thaw cycles (FTCs), and the results showed that the frost resistance of the matrix got better by addition of basalt fiber. Nam et al. [23] verified the effect of the PVA fiber and polypropylene fiber on durability performance of concrete under different FTCs; the results showed that the PVA fiber was more effective for frost resistance than the polypropylene fiber. Zeng et al. [24] studied the permeability of the steel fiber reinforced concrete (SFRC) under frost circumstance, and the results revealed that the impermeability of the matrix enhanced by addition of steel fiber. However, from the literature review, it can be seen that the systematic investigation of the fibers effect on the durability of concrete in cold regions is still rare.

Water plays a key role in durability problems of the concrete structures [25-27]. For any kinds of deterioration process, the expansion, cracking, and even peeling of concrete are inseparable from the influence of water. Almost all physical and chemical processes that affect the durability of concrete structures involve the transmission and distribution of water in concrete pores and cracks [28]. In addition, 
water is also a carrier for the migration and diffusion of corrosive media into the concrete. In the unsaturated state, especially, the water absorption process produced by capillary action becomes the main mechanism for the entry of water and water-soluble media into the concrete. Therefore, the water transport performance of concrete has received extensive attention [29-34]. The concrete structures may be damaged at the serviceability stage due to environmental factors $[35,36]$. Studying the transmission process of moisture in damaged concrete is an important prerequisite and basis for accurately carrying out durability evaluation and service life prediction of reinforced concrete structures $[37,38]$. Bao and Wang $[39,40]$ studied the influence of compressive load on water absorption of concrete and recycled aggregate concrete. The results showed that the compressive load demonstrated a noticeable influence on the amount of absorbed water of the matrix. Van Belleghem et al. [41] and Chen et al. [42] studied the influence of the cracks on water absorption of the concrete. The results showed that the water absorption of the matrix was enhanced significantly with the appearance of the cracks. In cold regions, with the deterioration caused by the frost circumstance, the microcracks occurred and propagated to intersect each other to form a large number of material migration channels, which increase the transmission speed of water, oxygen, and soluble harmful media [43]. Yang et al. [44] and Bao et al. [45] investigated the water transport properties of the concrete damaged by freeze-thaw cycles, and the results revealed that the water penetration rate of the matrix increased with the increasing of the frost damage. Gao et al. [46] studied the capillary water absorption of the recycled coarse aggregate concrete under frost environment. And the results demonstrated that obvious improvement of capillary water absorption capacity was obtained. The use of fibers could perhaps demonstrate positive influence on the transport properties of concrete in cold regions. However, studies regarding the effects of the fibers on water transport performance of the concrete under frost damage are still very rare.

In this paper, four types of SFRC were prepared to verify the fiber influence on frost damage of the matrix. By carrying out the rapid freeze-thaw test, the mass loss (ML), and the residual dynamic modulus of elasticity (RDME), the samples were investigated, respectively. In addition, the capillary water absorption (CWA) of the SFRC was also studied and the effect of the FTCs on water transport ability of the matrix was compared. It is expected that the study will contribute to improve durability performance of concrete in cold regions.

\section{Materials and Test Methods}

2.1. Mixture Design. The binder consisted of the Portland cement (P.O 42.5R) and fly ash. Coarse aggregate was crushed gravel with a distribution diameter of $5 \mathrm{~mm}$ to $20 \mathrm{~mm}$. The fine aggregate was natural river sand. The polycarboxylic superplasticizer was adopted, and the waterto-binder ratio was 0.5 . The basic mix proportion of the plain concrete without any reinforcement is shown in Table 1 . The hooked-ended steel fiber was adopted, and the contents of the fiber were $0 \mathrm{~kg} / \mathrm{m}^{3}, 20 \mathrm{~kg} / \mathrm{m}^{3}, 40 \mathrm{~kg} / \mathrm{m}^{3}$, and $60 \mathrm{~kg} / \mathrm{m}^{3}$, respectively. The physical properties of the steel fiber are shown in Table 2.

The mixing procedure was conducted according to CECS 13 [47]. First, the fine aggregates and coarse aggregates were homogenized by dry mixing for one minute, and then, the cement and fly ash were added $(+1$ minute of dry mixing). The cementitious materials and aggregates were mixed with an additional two minutes; the water mixed with the super plasticizer was poured slowly during this process. After that, the steel fibers were gradually added into the mixture; at last, all the materials were mixed for one minute. The whole mixing procedure took about eight minutes.

2.2. Freeze-Thaw Test. The fast freezing method was adopted in the freeze-thaw test following the guidelines of the standard [48]. The prism sample with the dimensions of $100 \mathrm{~mm} \times 100 \mathrm{~mm} \times 400 \mathrm{~mm}$ was used. The mass and dynamic modulus of elasticity (DME) of the specimen were measured after every 25 FTCs, and the measurement of the DME is shown in Figure 1. The test was stopped when the RDME of the specimen was less than $60 \%$ or the mass loss of the matrix exceeded 5\%. The ML and the RDME of the samples can be obtained according to the standard [48], as shown in (1) and (2).where, $\Delta W$ means the ML of the concrete, $\% ; W_{0}$ means the initial mass of the sample, $g ; W_{i}$ means the mass of the sample after $i$ FTCs, $g$.

$$
\Delta W=\frac{W_{0}-W_{i}}{W_{0}} \times 100,
$$

where $\Delta P$ means the RDME of the concrete, $\% ; P_{0}$ means the initial DME of the sample, GPa; $P_{i}$ means the DME of the sample after $i$ FTCs, GPa.

$$
\Delta P=\frac{P_{i}}{P_{0}} \times 100
$$

2.3. Capillary Water Absorption Test. The CWA test was conducted according to the guidelines of standard [49]. The cubic sample with the side length of $100 \mathrm{~mm}$ was adopted, for every 25 freeze-thaw cycles, three samples of each group were prepared, and the mean value was adopted for analysis. The absorbed water of the cementitious materials regarding the effect of gravity can be described using (3) [30, 50, 51]:

$$
\Delta W(\sqrt{t})=a[1-\exp (-b \sqrt{t})]
$$

where $\Delta W$ denotes the amount of capillary absorbed water per unit area; $t$ denotes the time of the capillary absorption; $a$ and $b$ denote the parameters, which can be obtained by fitting the experimental results. The time-dependent coefficient of CWA can be determined by finding the first derivative of (3) [30]:

$$
A(\sqrt{t})=\frac{d \Delta W(\sqrt{t})}{d(\sqrt{t})}=B_{\text {initial }} \exp (-b \sqrt{t}),
$$

where $A$ denotes the coefficient of CWA; $B_{\text {initial }}$ denotes the initial coefficient of CWA, $B_{\text {initial }}=a \times b$. 
TABLe 1: Basic mix proportion of the concrete $\left(\mathrm{kg} / \mathrm{m}^{3}\right)$.

\begin{tabular}{lccccc}
\hline Cement & Fly ash & Coarse aggregates & Fine aggregates & Water & Super plasticizer \\
\hline 390 & 155 & 822 & 848 & 273 & 5.5 \\
\hline
\end{tabular}

TABle 2: Physical properties of steel fiber.

\begin{tabular}{lccccc}
\hline Types & Length $(\mathrm{mm})$ & Diameter $(\mathrm{mm})$ & Aspect ratio & Modulus of elasticity $(\mathrm{GPa})$ & Tensile strength $(\mathrm{MPa})$ \\
\hline Steel fiber & 35 & 0.54 & 65 & 200 & 1345 \\
\hline
\end{tabular}

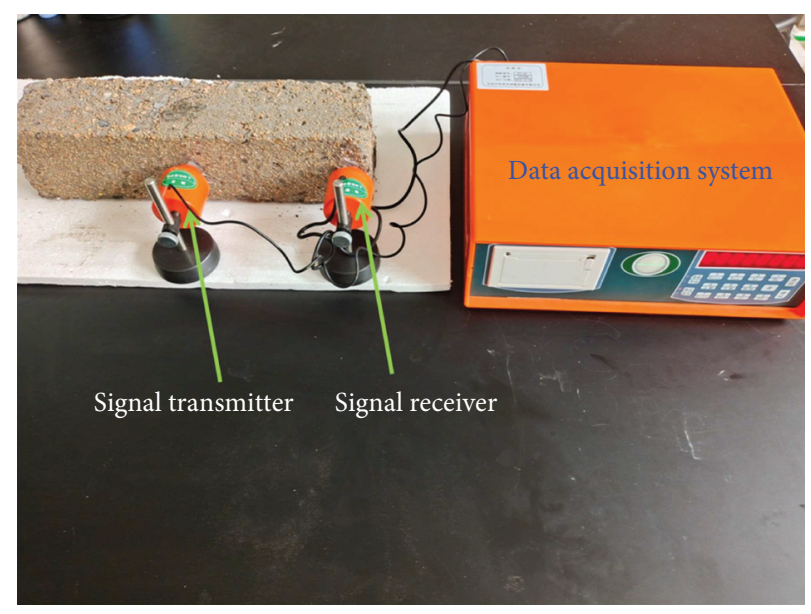

Figure 1: Measurement of the DME of the samples.

\section{Results and Discussion}

3.1. Slump, Air Content, and Compressive Strength. For the fresh concrete, the slump test and the air content test were conducted according to the guidelines [47]. For the compressive strength of the matrix, three cubic samples with the size of $150 \mathrm{~mm} \times 150 \mathrm{~mm} \times 150 \mathrm{~mm}$ were prepared for each group, and the uniaxial compression test was conducted according to the guidelines [52]. The slump, air content, and the compressive strength of the samples after $28 \mathrm{~d}$ are shown in Table 3.

From Table 3, we can observe that as the fiber content increased, the slump of the matrix decreased gradually. Compared with the PC, the slump of the SFRC with fiber dosage of $60 \mathrm{~kg} / \mathrm{m}^{3}$ decreased by $31 \%$; the air content of the fresh matrix increased as the fiber content enhanced. Compared with the PC, the slump of the SFRC60 increased by $65 \%$. While obvious difference was not observed for the compressive strength of the samples, it is revealed that the compressive strength of the matrix was not significantly affected by the steel fibers. The fiber influence on compressive strength agreed with the previous investigations on high performance concrete by Ding et al. [53].

3.2. Mass Loss of the Samples. The variation of the ML of the samples after different FTCs is shown in Figure 2.

From Figure 2, we can see the following: (i) For the samples of PC, the mass loss declines slowly when the FTCs were less than 100; the decrement of the mass loss is significant when the FTCs reach 125. The mass loss of the matrix corresponding to the FTCs of 100 is only $0.8 \%$; the mass loss of the matrix regarding the FTCs of 125 reaches to $2.7 \%$.

(ii) For the samples of macrofiber reinforced concrete, the mass loss is not observed; on the contrary, the mass of the samples demonstrates varying degrees of increment. For example, when the FTCs were 175 , the mass of SFRC40 and SFRC60 increase by $2.6 \%$ and $1.4 \%$, respectively.

(iii) Because the RDME of the samples reach the control line (see 3.3 Variation of the RDME of the samples), the test is stopped; the mass loss may not be an effective index for verifying the frost performance of SFRC.

The reasons may be that the deterioration features of concrete after frost attack include surface peeling off and cracking. The mass of the sample decreases due to the surface peeling off. The water can enter into the matrix through some of the new cracks. This phenomenon can compensate the mass loss caused by the surface peeling off. For the samples of PC, the surface peeling off is severe with the increment of FTCs; the ML of the samples is increasingly significant. For the macro-steel fiber reinforced concrete, the surface peeling off is restricted by the fibers, and some of the 
TABLE 3: Slump, air content, and compressive strength of the concrete.

\begin{tabular}{lcccc}
\hline Type & Steel fiber content $\left(\mathrm{kg} / \mathrm{m}^{3}\right)$ & Slump $(\mathrm{mm})$ & Air content $(\%)$ & Compressive strength $(\mathrm{MPa})$ \\
\hline PC & 0 & 160 & 2.0 & 37.1 \\
SFRC20 & 20 & 150 & 2.5 & 37.6 \\
SFRC40 & 40 & 125 & 3.0 & 38.2 \\
SFRC60 & 60 & 110 & 3.3 & 36.5 \\
\hline
\end{tabular}

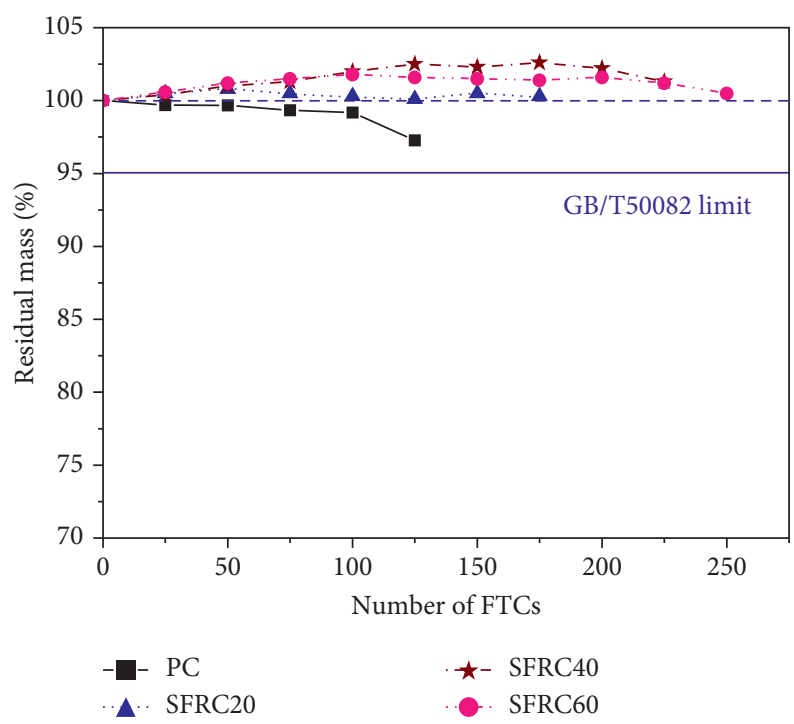

FIgURE 2: Variation of the ML of different samples during FTCs.

spalling concrete remains loosely bonded by the fibers. The phenomenon demonstrates a negative influence on the effectiveness of ML to verify the frost damage of SFRC.

3.3. Variation of the RDME of the Samples. The RDME of the samples after different FTCs are shown in Figure 3.

From Figure 3, it can be seen that with, increasing the FCTs, the RDME of each group shows a downward trend, and the RDME of the PC specimens decreases faster than that of the steel fiber reinforced samples. With the increment of steel fiber dosage, the RDEM of the specimens slowed down gradually. For example, when the FTCs is 100, the RDME of the PC, SFRC20, SFRC40, and SFRC60 are 70.5\%, $74.8 \%, 84.1 \%$, and $89.8 \%$, respectively. Compared with PC, the RDME of the SFRC20, SFRC40, and SFRC60 enhanced by $6 \%, 19 \%$, and $27 \%$, respectively. When the FTCs are 125 , the RDME of the PC, SFRC20, SFRC40, and SFRC60 are $57.4 \%, 67.2 \%, 80.2 \%$, and $85.5 \%$, respectively. Compared with the FTCs of 100, the RDME of PC, SFRC20, SFRC40, and SFRC60 decreased by 19\%, 10\%, 5\%, and 5\%, respectively. It means that the frost resistance of the matrix can be enhanced noticeably with the strong positive influence of steel fibers. The reason may be attributed to that the development of the microcracks caused by the FTCs in the matrix are limited with the randomly distributed fibers; in addition, the number of closed pores in the concrete are also increased with addition of fibers, which can relieve the frost pressure in the matrix. Thereby, the damage of the concrete caused by the FTCs is reduced.

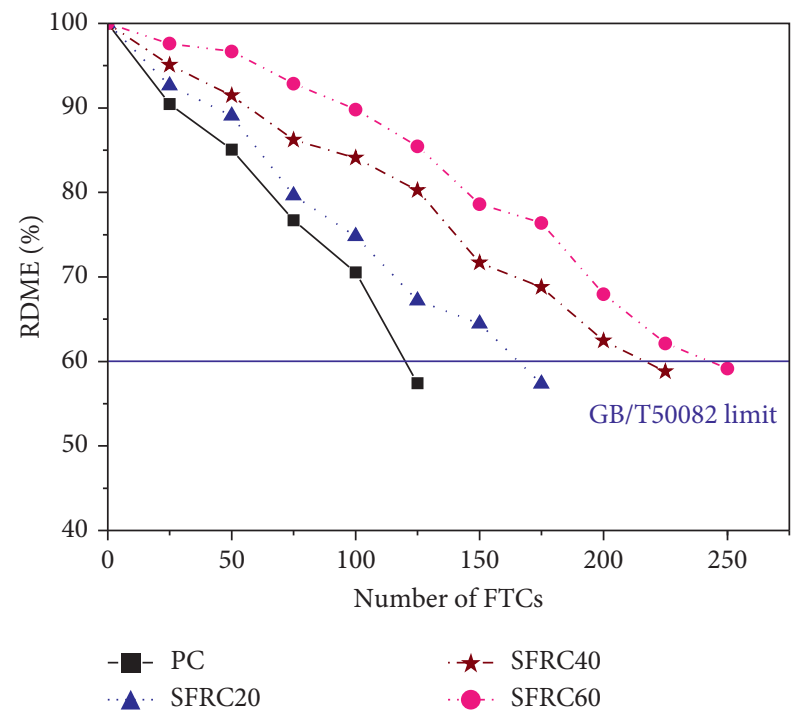

FIgURE 3: Variation of the RDME of the samples after different FTCs.

According to the analysis of mass loss and the RDME of the samples, it can be seen that the experiment was stopped due to the decrement of the DEM and the loss of mass as the indices of degradation under FTCS were not effective for macro-steel fiber reinforced concrete.

The frost resistance of the concrete can also be verified by the frost resistance grade $F$ and the durability factor $D_{F}$ $[48,54]$. The frost resistance grade $F$ means the maximum 
FTCs of the samples under the fast freezing test. The durability factor $D_{F}$ can be obtained by the following equation:

$$
D_{F}=\frac{0.6 \times N}{300},
$$

where $N$ denotes the maximum FTCs of the samples.

The frost resistance grade $F$, the durability factor $D_{F}$, and the applicable condition regarding the $D_{F}$ of the SFRC are listed in Table 4.

From Table 4, we can see that the improvement of the frost resistance grade $F$ and the durability factor $D_{F}$ is remarkable as the fiber content increases. Compared with the indexes of PC, the values of $F$ and $D_{F}$ of the SFRC20, SFRC40, and SFRC60 increase by 50\%, 100\%, and 125\%, respectively. In addition, the durability performance of the matrix is enhanced with the increment of steel fiber dosage, and the matrix can be adopted in the frozen area. The concrete can service for a long time under different frozen circumstances when the dosage of the basalt fiber is up to $60 \mathrm{~kg} / \mathrm{m}^{3}$.

3.4. Damage Model under FTCs. When concrete is subjected to FTCs, the internal stress generated by hydraulic pressure and osmotic pressure is repeated. The microcracks produced by a FTC are not enough to cause global damage to the concrete. The ultimate failure of concrete is caused by the frost damage accumulated from the FTCs. The mechanism is similar to the fatigue failure of the concrete $[55,56]$. The frost damage of the concrete can be obtained by

$$
D_{n}=1-\frac{E_{n}}{E_{0}}
$$

where $D_{n}$ means the frost damage of the concrete corresponding to the FTCs of $n ; E_{0}$ means the DME of the concrete without influence of FTCs; $E_{n}$ means the DME of the concrete regarding the FTCs of $n$.

The frost damage values $D_{\mathrm{n}}$ of the samples corresponding to the different FTCs is shown in Figure 4.

From Figure 4, it can be seen that the frost damage of the matrix increases with the increasing of the FTCs, and the values of $D_{n}$ decrease with the increment of the fiber dosage.

The Weibull distribution used for lifetime prediction may be feasible to illustrate the relationship between the frost damage of the matrix and the number of FTCs. The distribution function of the Weibull distribution is shown as follows [57-59]:

$$
F(n)=1-\exp \left[-\left(\frac{n}{\eta}\right)^{\beta}\right],
$$

where $F(n)$ means the frost damage of the matrix; $n$ means the FTCs; $\eta$ means the parameter relevant to the guaranteed life; $\beta$ means the parameter relevant to the shape of the Weibull distribution.

Equation (7) can be transformed into

$$
1-F(n)=\exp \left[-\left(\frac{n}{\eta}\right)^{\beta}\right] .
$$

Taking natural logarithm for both sides of (8) and moving the negative sign to the left side of the equation gives the following:

$$
-\ln [1-F(n)]=\left(\frac{n}{\eta}\right)^{\beta} .
$$

Equation (10) is obtained by taking natural logarithm again for both sides of (9):

$$
\ln [-\ln (1-F(n))]=\beta \ln n-\beta \ln \eta .
$$

Setting $Y=\ln [-\ln (1-F(n))], X=\ln n, a=\beta \ln \eta$, then

$$
Y=\beta X-a \text {. }
$$

Therefore, the statistical distribution of the frost damage of the SFRC can be evaluated by (11).

The fitting results of the samples are listed in Figure 5 and Table 5.

From Figure 5 and Table 5, we can see that the correlation coefficients $R^{2}$ of all the samples are larger than 0.950 , and it means that there is a significant linear relationship between $X$ and $Y$. Therefore, the frost damage distribution of the concrete regarding the number of FTCs follows the Weibull distribution. The Weibull distribution can be adopted to predict the damage of the steel fiber reinforced concrete in cold regions.

\subsection{Capillary Absorption Capacity of the Samples.} Because the maximum FTCs of the PC are 100, the maximum FTCs of the samples for capillary water absorption test were set as 100. In order to evaluate the consequence of steel fiber addition on the water transport properties of the concrete under frost damage, the amount of absorbed water of different samples corresponding to the same FTCs is shown in Figure 6, respectively. With the intention of analyzing the fiber influence quantitatively, the amount of absorbed water of the samples regarding the square root of time $1.0 \mathrm{~h}^{0.5}, 2.0 \mathrm{~h}^{0.5}, 4.9 \mathrm{~h}^{0.5}, 9.8 \mathrm{~h}^{0.5}$, and $13.0 \mathrm{~h}^{0.5}$ is listed in Table 6.

From Figure 6 and Table 6, some interesting points can be obtained as follows.

(i) When the FTCs are 0, the amount of absorbed water of the PC, SFRC20, SFRC40, and SFRC60 is similar. It means that the addition of the steel fiber shows no obvious influence on the CWA of concrete without the effect of FTCs.

(ii) When the FTCs are 25, the differences of the amount of absorbed water of the matrix emerge clearly, and the amount of absorbed water of the PC is greater than that of the steel fiber reinforced samples during the experiment. For example, compared with SFRC60, the amount of absorbed water of PC corresponding to the square root of time $1.0 \mathrm{~h}^{0.5}, 2.0 \mathrm{~h}^{0.5}, 4.9 \mathrm{~h}^{0.5}, 9.8 \mathrm{~h}^{0.5}$, and $13.0 \mathrm{~h}^{0.5}$ increases by $187 \%, 161 \%, 116 \%, 57 \%$, and $50 \%$, respectively. Additionally, it also can be seen that the positive influence of the fiber addition on 
TABLE 4: Frost durability factors and applicable condition of the SFRC.

\begin{tabular}{lccc}
\hline No. & Frost resistance grade $F$ & Durability factor $D_{F}(\%)$ & Applicable conditions \\
\hline PC & 100 & 20 & Nonfrozen area \\
SFRC20 & 150 & 30 & Nonfrozen area \\
SFRC40 & 200 & 40 & $\begin{array}{c}\text { Moderate saturated and slightly frozen area with design life of } 30 \text { years } \\
\text { Moderate saturated and frozen area with design life of } 30 \text { years } \\
\text { SFRC60 }\end{array}$ \\
& 225 & 45 & Moderate saturated and slightly frozen area with design life of 50 years \\
\hline
\end{tabular}

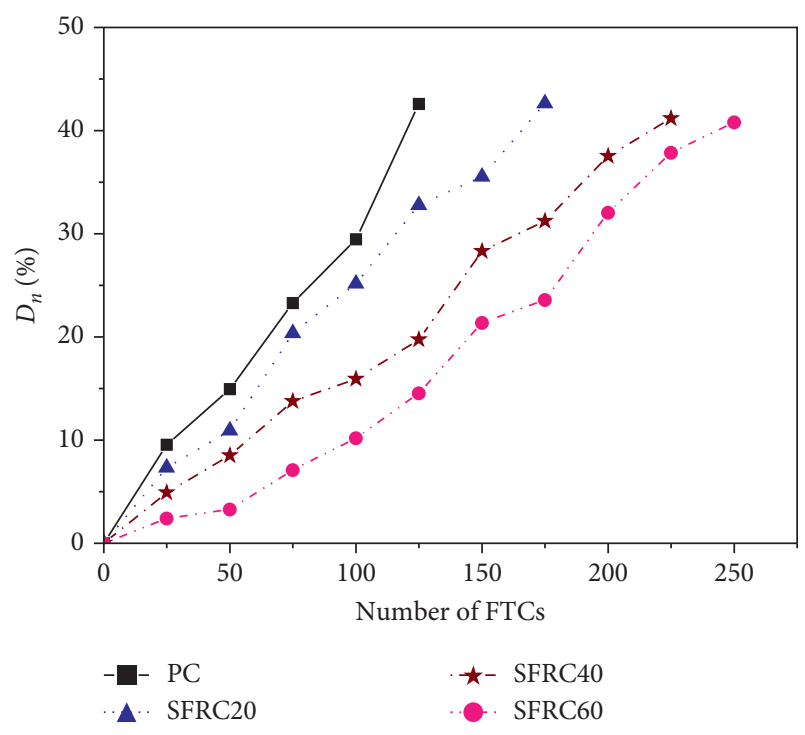

Figure 4: Frost damage of the samples with different FTCs.

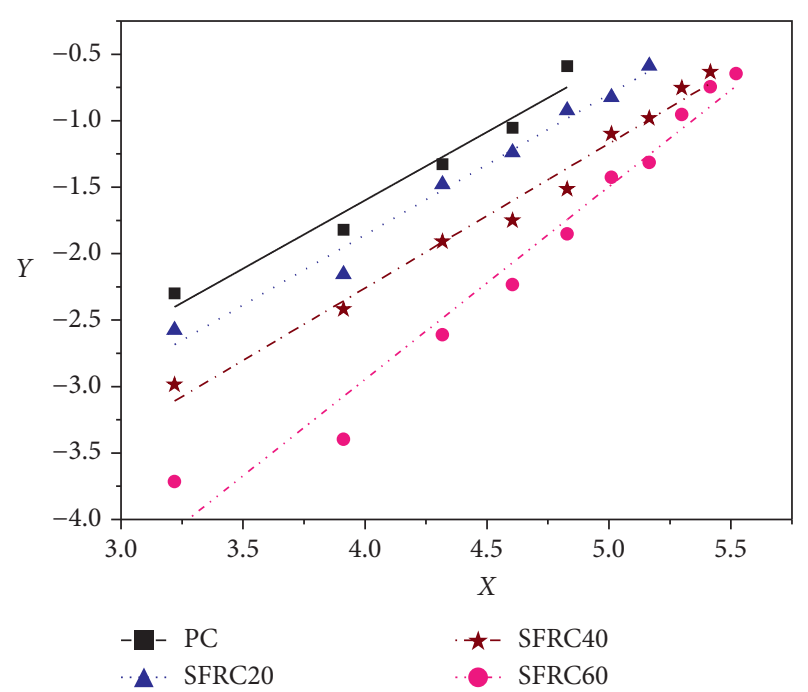

FIgURE 5: Linear regression of frost damage in Weibull distribution.

restriction of moisture transmission is more obvious at the initial stage of the CWA test.

(iii) When the FTCs are 50, the increment of the amount of absorbed water of PC is significant during the experiment. The difference of the amount of absorbed water of the macro-steel fiber reinforced concrete is not noticeable. For example, compared
TABLE 5: Fitting results of the frost damage in Weibull distribution.

\begin{tabular}{lccc}
\hline Types & $\beta$ & $a$ & $R^{2}$ \\
\hline PC & 1.027 & 5.709 & 0.965 \\
SFRC20 & 1.057 & 6.087 & 0.980 \\
SFRC40 & 1.088 & 6.610 & 0.982 \\
SFRC60 & 1.451 & 8.750 & 0.967 \\
\hline
\end{tabular}

with SFRC60, the amount of absorbed water of PC corresponding to the square root of time $1.0 \mathrm{~h}^{0.5}$, $2.0 \mathrm{~h}^{0.5}, 4.9 \mathrm{~h}^{0.5}, 9.8 \mathrm{~h}^{0.5}$, and $13.0 \mathrm{~h}^{0.5}$ increases by $152 \%, 128 \%, 114 \%, 113 \%$, and $123 \%$, respectively. The reason may be that more internal cracks emerged because the FTCs and the frost damage give more paths for water entering the matrix. The addition of macro-steel fiber can bridge the microcracks caused by FTCs and reduce the deterioration.

(iv) When the FTCs are 75, the substantial increase of the amount of absorbed water of the SFRC20 comes out. The amount of absorbed water of the SFRC40 and SFRC60 remains low. Compared with SFRC60, the amount of absorbed water of SFRC20 corresponding to the square root of time $1.0 \mathrm{~h}^{0.5}, 2.0 \mathrm{~h}^{0.5}$, $4.9 \mathrm{~h}^{0.5}, 9.8 \mathrm{~h}^{0.5}$, and $13.0 \mathrm{~h}^{0.5}$ increases by $192 \%$, $161 \%, 176 \%, 127 \%$, and $115 \%$, respectively. The phenomenon reflects that, with the increasing of fiber dosage, the frost damage of the concrete can be reduced.

(v) When the FTCs are 100, the difference of the amount of absorbed water among the four types of samples is great during the test. When the square root of time is $1.0 \mathrm{~h}^{0.5}$, compared with $\mathrm{PC}$, the amount of absorbed water of SFRC20, SFRC40 and SFRC60 decreases by 31\%, 51\%, and 70\%, respectively. When the square root of time is $2.0 \mathrm{~h}^{0.5}$, the amount of absorbed water of SFRC20, SFRC40, and SFRC60 decreases by $38 \%, 52 \%$, and $71 \%$, respectively, compared with that of the PC. When the square root of time is $4.9 \mathrm{~h}^{0.5}$, the amount of absorbed water of SFRC20, SFRC40, and SFRC60 decreases by $10 \%, 26 \%$, and $60 \%$, respectively, compared with that of PC. When the square root of time is $9.8 \mathrm{~h}^{0.5}$, the amount of absorbed water of SFRC20, SFRC40, and SFRC60 decreases by $11 \%$, $26 \%$, and $60 \%$, respectively, compared with that of the PC. When the square root of time is $13.0 \mathrm{~h}^{0.5}$, the amount of absorbed water of SFRC20, SFRC40, and SFRC60 decreases by $13 \%, 27 \%$, and $60 \%$, 


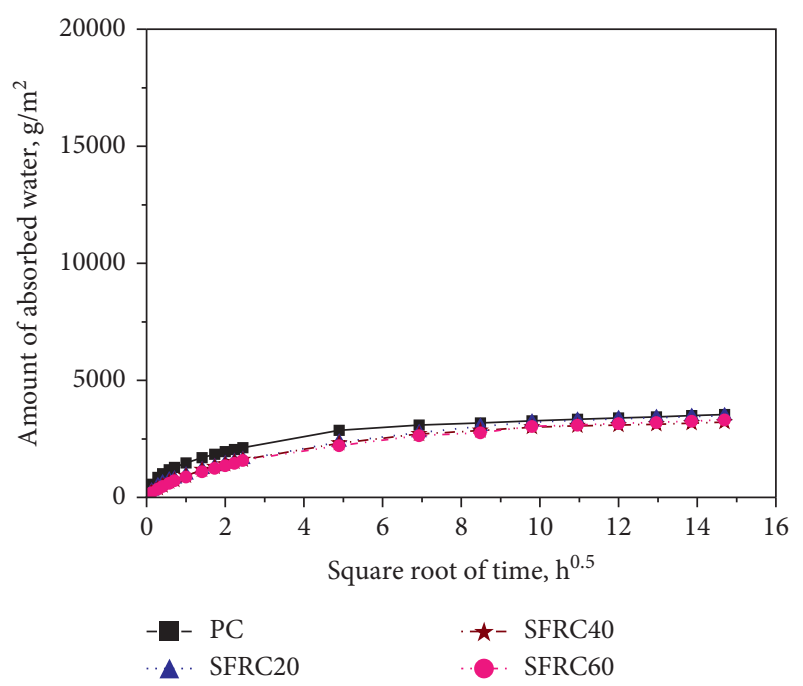

(a)

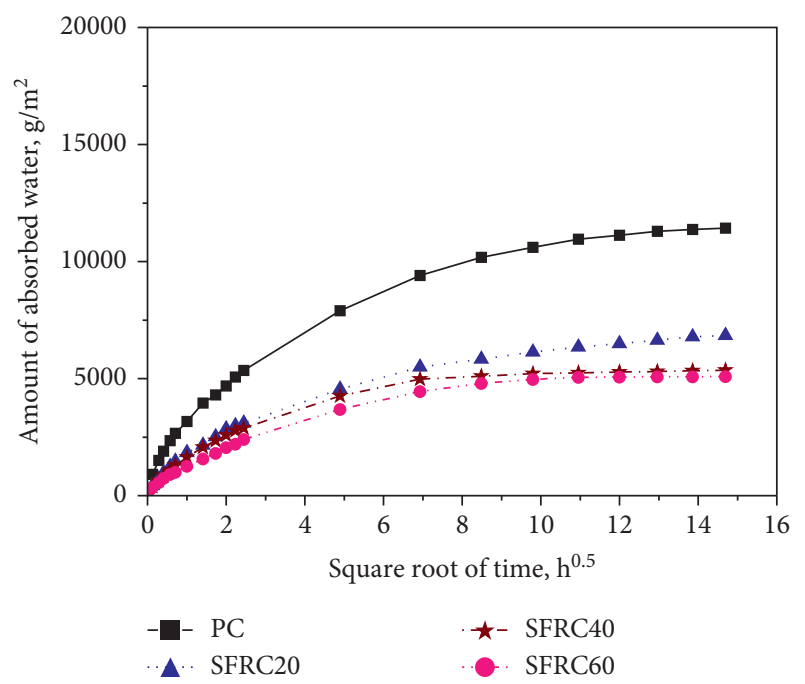

(c)

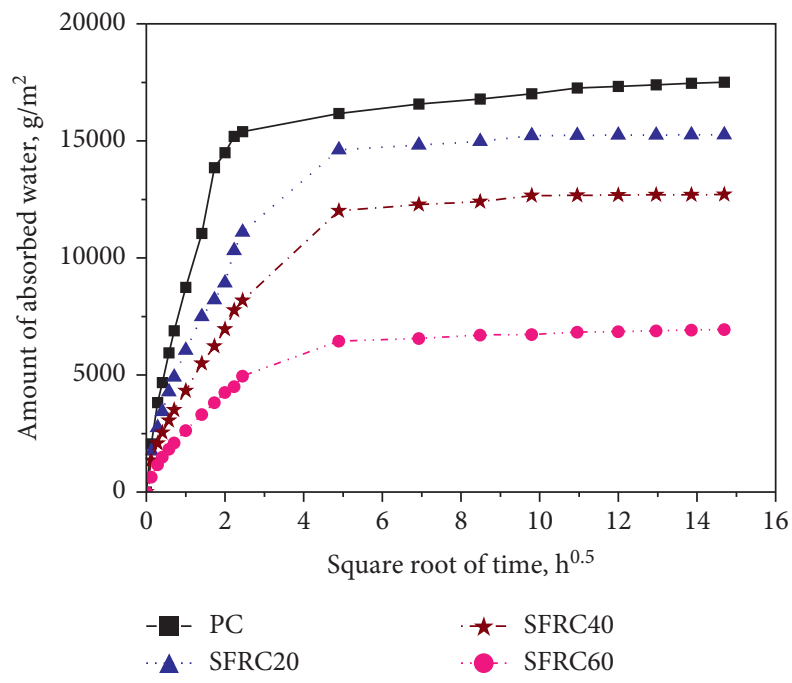

(e)

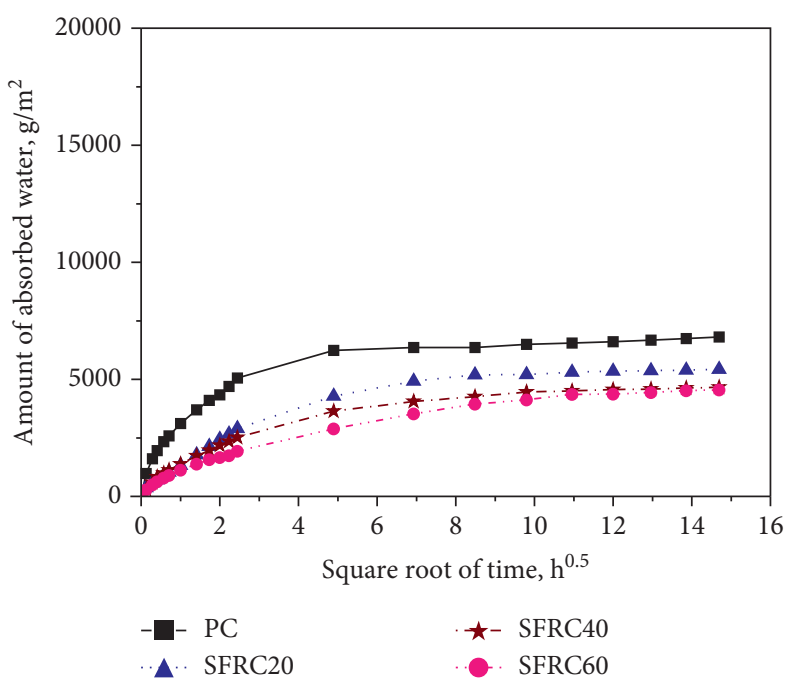

(b)

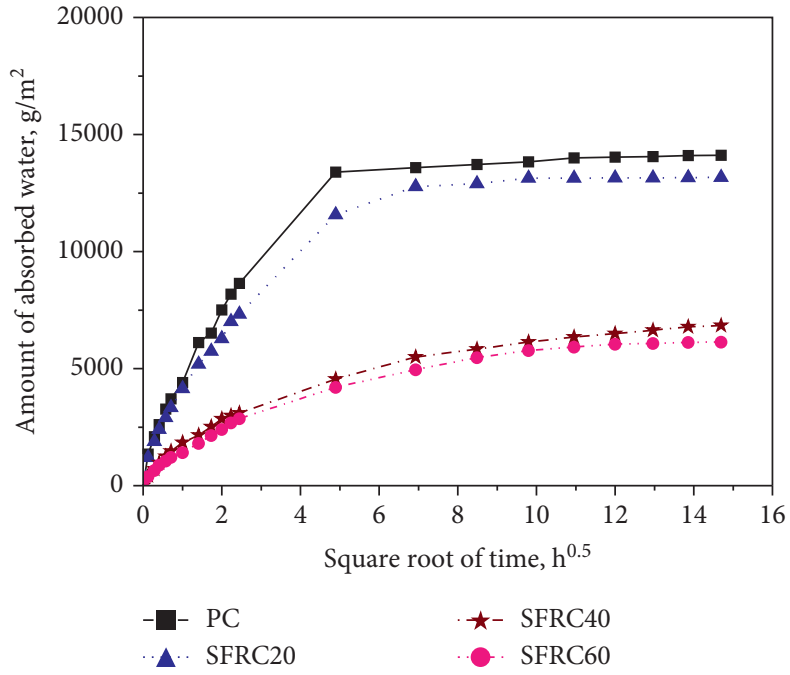

(d) 
TABle 6: Amount of absorbed water of the samples corresponding to different times.

\begin{tabular}{|c|c|c|c|c|c|c|}
\hline \multirow{2}{*}{ FTCs } & \multirow{2}{*}{ Types } & \multicolumn{5}{|c|}{ Square root of time $\left(\mathrm{h}^{0.5}\right)$} \\
\hline & & 1.0 & 2.0 & 4.9 & 9.8 & 13.0 \\
\hline \multirow{4}{*}{0} & PC & 1469 & 1960 & 2865 & 3271 & 3437 \\
\hline & SFRC20 & 950 & 1441 & 2359 & 3209 & 3404 \\
\hline & SFRC40 & 925 & 1413 & 2320 & 2998 & 3118 \\
\hline & SFRC60 & 875 & 1359 & 2209 & 3033 & 3204 \\
\hline \multirow{4}{*}{25} & PC & 3115 & 4336 & 6238 & 6494 & 6671 \\
\hline & SFRC20 & 1330 & 2441 & 4278 & 5205 & 5366 \\
\hline & SFRC40 & 1384 & 2180 & 3642 & 4456 & 4584 \\
\hline & SFRC60 & 1120 & 1660 & 2893 & 4129 & 4436 \\
\hline \multirow{4}{*}{50} & PC & 3169 & 4690 & 7897 & 10608 & 11366 \\
\hline & SFRC20 & 1846 & 2851 & 4547 & 6136 & 6790 \\
\hline & SFRC40 & 1636 & 2585 & 4255 & 5210 & 5334 \\
\hline & SFRC60 & 1259 & 2057 & 3687 & 4971 & 5084 \\
\hline \multirow{4}{*}{75} & PC & 4405 & 7503 & 13392 & 13827 & 14099 \\
\hline & SFRC20 & 4149 & 6284 & 11573 & 13131 & 13156 \\
\hline & SFRC40 & 1846 & 2851 & 4547 & 6136 & 6790 \\
\hline & SFRC60 & 1420 & 2410 & 4200 & 5780 & 6120 \\
\hline \multirow{4}{*}{100} & PC & 8744 & 14491 & 16164 & 17011 & 17460 \\
\hline & SFRC20 & 6059 & 8932 & 14622 & 15227 & 15256 \\
\hline & SFRC40 & 4324 & 6958 & 12009 & 12661 & 12702 \\
\hline & SFRC60 & 2631 & 4254 & 6445 & 6731 & 6918 \\
\hline
\end{tabular}

TABLE 7: Fitting results of CWA with square root of time.

\begin{tabular}{lcccccc}
\hline \multirow{2}{*}{ Types } & & \multicolumn{5}{c}{ FTCs } \\
& & 0 & 25 & 50 & 75 & 100 \\
\hline \multirow{3}{*}{ PC } & $a$ & 3332 & 6555 & 11450 & 14247 & 17216 \\
& $b$ & 0.508 & 0.626 & 0.275 & 0.399 & 0.809 \\
& $R^{2}$ & 0.960 & 0.985 & 0.991 & 0.994 & 0.992 \\
\hline \multirow{3}{*}{ SFRC20 } & $a$ & 3454 & 5526 & 6771 & 13432 & 15300 \\
& $b$ & 0.274 & 0.297 & 0.262 & 0.353 & 0.502 \\
& $R^{2}$ & 0.988 & 0.999 & 0.993 & 0.994 & 0.994 \\
\hline \multirow{3}{*}{ SFRC40 } & $a$ & 3159 & 4620 & 5385 & 6771 & 12828 \\
& $b$ & 0.306 & 0.331 & 0.338 & 0.262 & 0.423 \\
& $R^{2}$ & 0.994 & 0.996 & 0.997 & 0.993 & 0.994 \\
\hline \multirow{3}{*}{ SFRC60 } & $a$ & 3263 & 4671 & 5304 & 6306 & 6874 \\
& $b$ & 0.269 & 0.225 & 0.256 & 0.244 & 0.497 \\
& $R^{2}$ & 0.993 & 0.993 & 0.996 & 0.996 & 0.997 \\
\hline
\end{tabular}

respectively compared with that of the PC. It means that the ability of absorbed water of the matrix decreases with the increment of fiber content.

The time-dependent coefficient of the CWA of different kinds of samples can be obtained according to (4) and (5). The fitting results are shown in Table 7.

From Table 7, we can see that the values of $R^{2}$ of seventeen groups are larger than 0.990 , and only three groups of the results are between 0.960 and 0.990 . It can be revealed that, for SFRC, the relationship between the amount of absorbed water and the square root of time follows (4).
According to the fitting results in Table 7, the timedependent coefficients of the CWA regarding different FTCs are shown in Figure 7.

From Figure 7, we can see that, for different FTCs, the variation of the CWA coefficient demonstrates the similar varying tendency and the CWA coefficient decreases with the increment of test time. With the increment of FTCs, the CWA coefficient of the PC is greatly larger than the macrosteel fiber reinforced samples for the early period of the test. When the square root of time is larger than $6.9 \mathrm{~h}^{0.5}$, the difference is not significant in the coefficient of the CWA of different samples. Additionally, when the FTCs are 100, the initial coefficient of CWA of the PC and the SFRC20 are both larger than $6000 \mathrm{~g} /\left(\mathrm{m}^{2} \cdot \mathrm{h}^{0.5}\right)$. Therefore, the dimension of the $\mathrm{y}$-coordinate increases to $18000 \mathrm{~g} /\left(\mathrm{m}^{2} \cdot \mathrm{h}^{0.5}\right.$ ) (see Figure 6(e)). For the purpose of quantifying the influence of fiber dosage on initial coefficient of capillary absorption of the matrix, the initial coefficient of CWA corresponding to different FTCs is shown in Figure 8.

From Figure 8, the following can be seen.

In general, the values of $B_{\text {initial }}$ increase with the increasing of the number of FTCs. For the samples of PC, the value of $B_{\text {initial }}$ corresponding to the FTCs of 50 is smaller than the value under the FTCs of 25. The reasons may be attributed to the peeling off of the surface of the samples. For the samples of PC and SFRC20, the values of $B_{\text {initial }}$ increase in a pronounced manner when the number of FTCs is above 50. For the samples of SFRC40 and SFRC40, the noticeable increment of the $B_{\text {initial }}$ is observed when the number of 


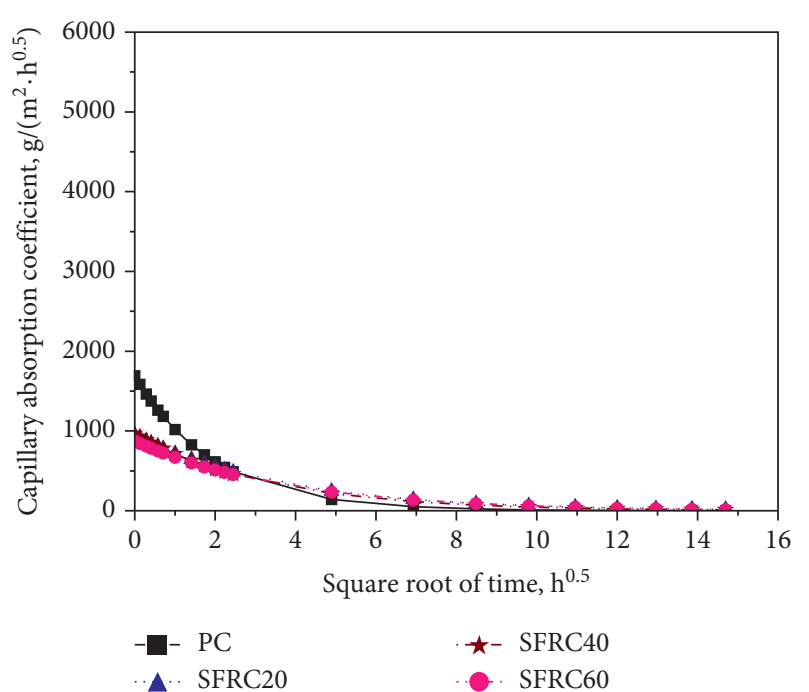

(a)

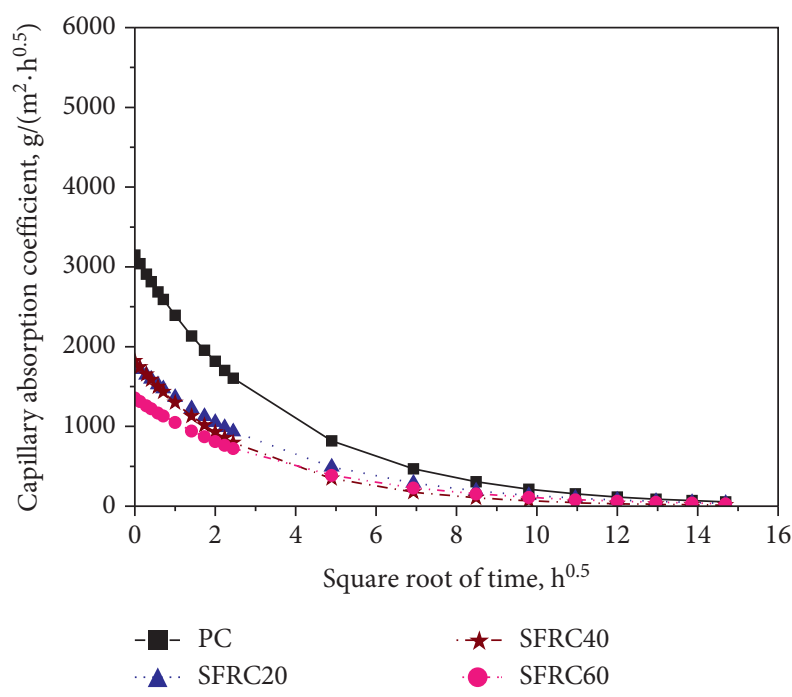

(c)

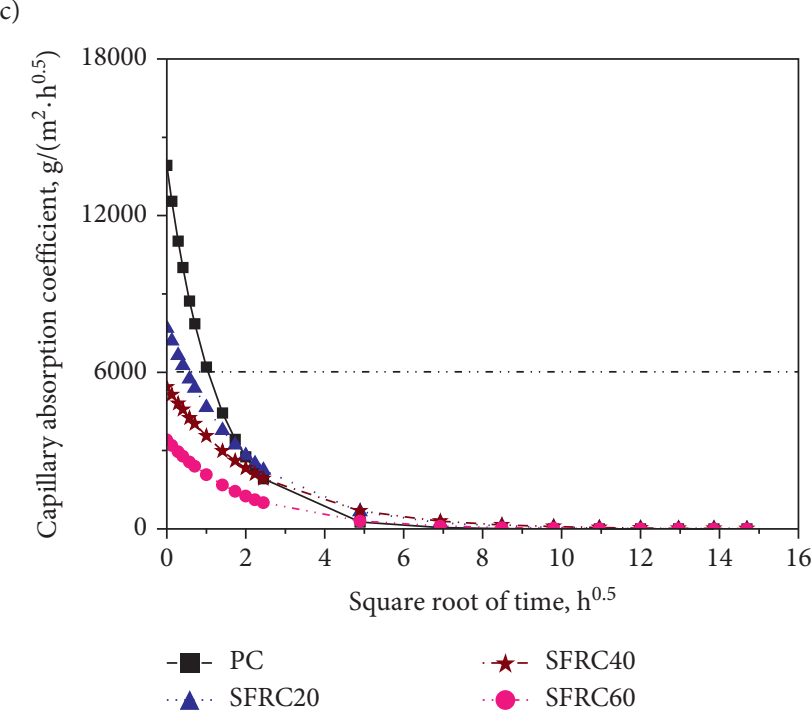

(e)

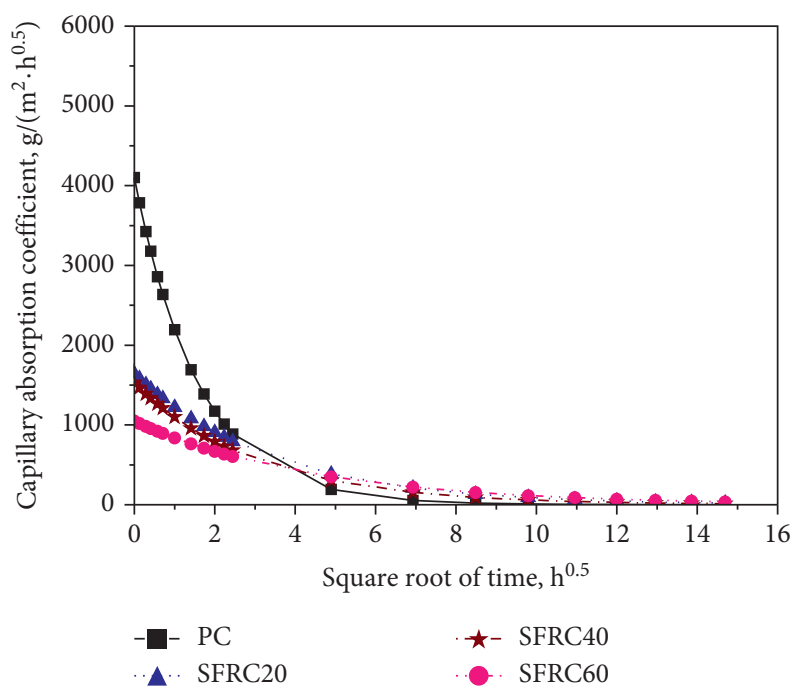

(b)

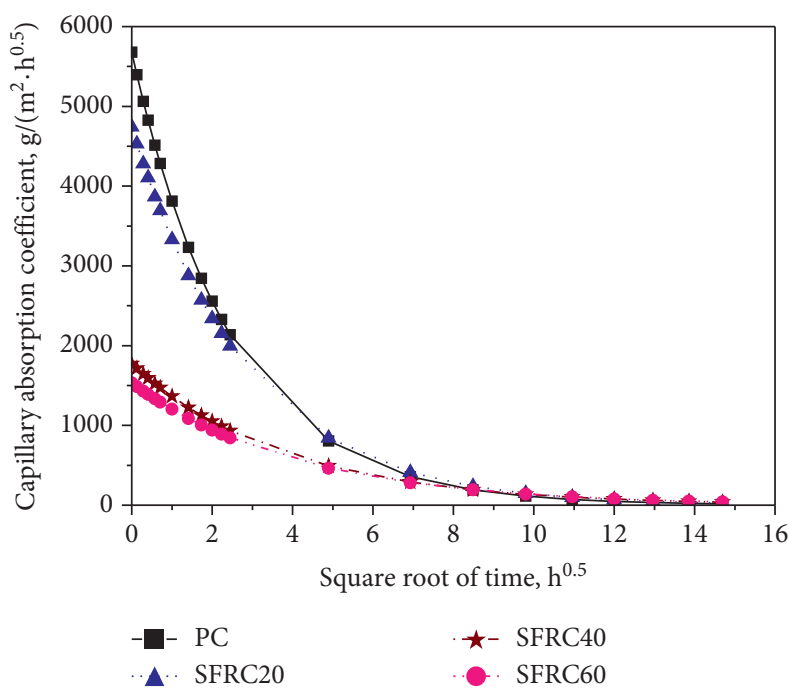

(d) 


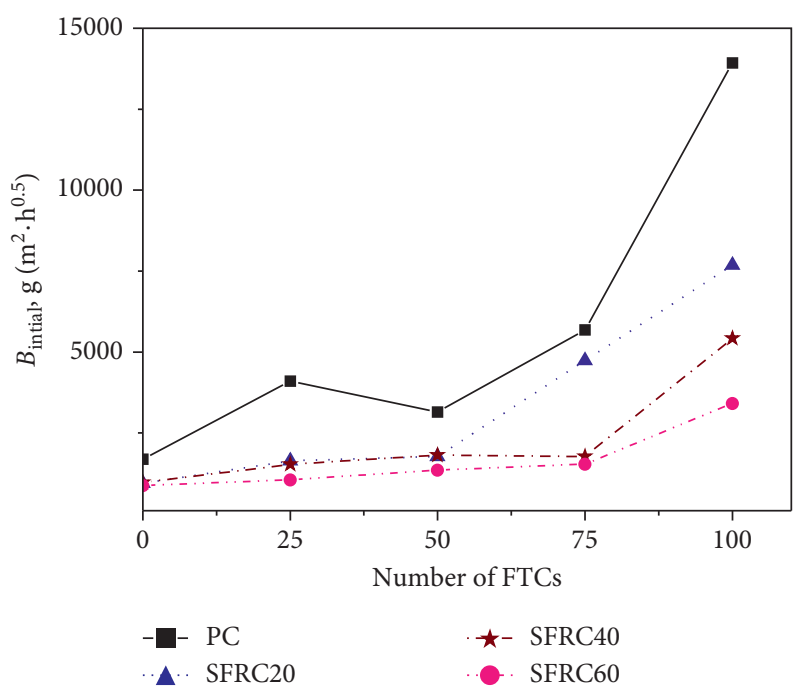

FIGURE 8: FTCs influence on initial coefficient of CWA.

FTCs is larger than 75 . The values of the $B_{\text {initial }}$ decrease with the increment of macrofiber dosage. Take the FTCs of 100 as an example: the $B_{\text {initial }}$ of the PC, SFRC20, SFRC40, and SFRC60 are $13928 \mathrm{~g} /\left(\mathrm{m}^{2} \cdot \mathrm{h}^{0.5}\right), \quad 7681 \mathrm{~g} /\left(\mathrm{m}^{2} \cdot \mathrm{h}^{0.5}\right), \quad 5426 \mathrm{~g} /$ $\left(\mathrm{m}^{2} \cdot \mathrm{h}^{0.5}\right)$ and $3416 \mathrm{~g} /\left(\mathrm{m}^{2} \cdot \mathrm{h}^{0.5}\right)$, respectively. Compared with the value of PC, the values of $B_{\text {initial }}$ of SFRC20, SFRC40, and SFRC60 decrease by 45\%, 61\%, and 75\%, respectively.

\section{Conclusions}

According to the experimental and analytical investigation, the following conclusion can be drawn.

(1) For the rapid freeze-thaw test, the descent speed of the RDME of the concrete is restricted with the fiber dosage. The mass loss may be not an effective index as the deterioration features for macro-steel fiber reinforced concrete.

(2) The frost damage of the concrete is reduced by addition of macro-steel fibers. Compared with PC, the frost resistance grade of SFRC60 increases by $125 \%$, and the concrete reinforced by macro steel fibers can be adopted in several conditions of cold climates.

(3) The relationship between the frost damage factor $D_{n}$ and the number of FTCs of steel fiber reinforced concrete follows the Weibull distribution.

(4) The transport properties of the concrete increase noticeably with the repeated freezing and thawing. The CWA of the matrix increases with the increasing of FTCs. The amount of absorbed water and the coefficient of CWA of the concrete decrease with the steel fiber dosage.

(5) Due to the strong ability to restrict the crack propagation in the matrix, the addition of steel fiber demonstrates positive effects on the frost performance of concrete; therefore, the fiber reinforced concrete may be a choice for concrete structures in cold regions.

\section{Data Availability}

The data used to support the investigations of this study are available from the corresponding author upon request.

\section{Conflicts of Interest}

The authors declare that they have no conflicts of interest regarding the publication of this paper.

\section{Acknowledgments}

The authors would like to give their appreciation to the Educational Department of Liaoning Province, China (grant: LJ2019QL010), Liaoning Technical University, China (grant: LNTU20TD-12), and National Natural Science Foundation of China (grant: 51578109).

\section{References}

[1] A. Bentur and S. Mindess, Fibre Reinforced Cementitious Composites, CRC Press, Boca Raton, FL, USA, 2006.

[2] P. Soroushian and Z. Bayasi, "Fiber type effects on the performance of steel fiber reinforced concrete," Materials Journal, vol. 88, no. 2, pp. 129-134, 1991.

[3] J. Thomas and A. Ramaswamy, "Mechanical properties of steel fiber-reinforced concrete," Journal of Materials in Civil Engineering, vol. 19, no. 5, pp. 385-392, 2007.

[4] Z. Marcalikova, R. Cajka, V. Bilek, D. Bujdos, and O. Sucharda, "Determination of mechanical characteristics for fiber-reinforced concrete with straight and hooked fibers," Crystals, vol. 10, no. 6, p. 545, 2020.

[5] J. Eidan, I. Rasoolan, A. Rezaeian, and D. Poorveis, "Residual mechanical properties of polypropylene fiber-reinforced concrete after heating," Construction and Building Materials, vol. 198, pp. 195-206, 2019.

[6] L. Chen, X. Zhang, and G. Liu, "Analysis of dynamic mechanical properties of sprayed fiber-reinforced concrete based on the energy conversion principle," Construction and Building Materials, vol. 254, Article ID 119167, 2020.

[7] H. Kasagani and C. B. K. Rao, "Effect of graded fibers on stress strain behaviour of Glass Fiber Reinforced Concrete in tension," Construction and Building Materials, vol. 183, pp. 592-604, 2018.

[8] M. Khan, M. Cao, and M. Ali, "Effect of basalt fibers on mechanical properties of calcium carbonate whisker-steel fiber reinforced concrete," Construction and Building Materials, vol. 192, pp. 742-753, 2018.

[9] B. Li, L. Xu, Y. Shi, Y. Chi, Q. Liu, and C. Li, "Effects of fiber type, volume fraction and aspect ratio on the flexural and acoustic emission behaviors of steel fiber reinforced concrete," Construction and Building Materials, vol. 181, pp. 474-486, 2018.

[10] J.-H. Lee, "Influence of concrete strength combined with fiber content in the residual flexural strengths of fiber reinforced concrete," Composite Structures, vol. 168, pp. 216-225, 2017.

[11] V. Afroughsabet, L. Biolzi, and T. Ozbakkaloglu, "Highperformance fiber-reinforced concrete: a review," Journal of Materials Science, vol. 51, no. 14, pp. 6517-6551, 2016.

[12] M. Milovancevic, N. Denić, B. Ćirković, Z. Nešić, M. Paunović, and J. Stojanović, "Prediction of shear debonding strength of concrete structure with 
high-performance fiber reinforced concrete," Structures, vol. 33, pp. 4475-4480, 2021.

[13] K. Sijavandi, M. K. Sharbatdar, and A. Kheyroddin, "Experimental evaluation of flexural behavior of high-performance fiber reinforced concrete beams using GFRP and high strength steel bars," Structures, vol. 33, pp. 4256-4268, 2021.

[14] J. Liu, Y. Jia, and J. Wang, "Experimental study on mechanical and durability properties of glass and polypropylene fiber reinforced concrete," Fibers and Polymers, vol. 20, no. 9, pp. 1900-1908, 2019.

[15] R. D. Toledo Filho, E. A. B. Koenders, S. Formagini, and E. M. R. Fairbairn, "Performance assessment of ultra high performance fiber reinforced cementitious composites in view of sustainability," Materials and Design, vol. 36, pp. 880-888, 2012.

[16] N. Banthia and A. Bhargava, "Permeability of stressed concrete and role of fiber reinforcement," ACI Materials Journal, vol. 104, no. 1, pp. 70-76, 2007.

[17] C. G. Berrocal, K. Lundgren, and I. Löfgren, "Corrosion of steel bars embedded in fibre reinforced concrete under chloride attack: state of the art," Cement and Concrete Research, vol. 80, pp. 69-85, 2016.

[18] D. Li and S. Liu, "Macro polypropylene fiber influences on crack geometry and water permeability of concrete," Construction and Building Materials, vol. 231, Article ID 117128, 2020.

[19] Y. Ding, D. Li, and Y. Zhang, "Quantitative analysis of macro steel fiber influence on crack geometry and water permeability of concrete," Composite Structures, vol. 187, pp. 325-335, 2018.

[20] D. Li, Y. Ding, Q. Wang, Y. Zhang, C. Azevedo, and Y. Zhang, "Hybrid effect of fibre mesh and short fibres on the biaxial bending behaviour of TRC," Magazine of Concrete Research, vol. 71, no. 16, pp. 869-880, 2019.

[21] H. Ma, H. Yu, C. Li, Y. Tan, W. Cao, and B. Da, "Freeze-thaw damage to high-performance concrete with synthetic fibre and fly ash due to ethylene glycol deicer," Construction and Building Materials, vol. 187, pp. 197-204, 2018.

[22] W. Li, H. Liu, B. Zhu, X. Lyu, X. Gao, and C. Liang, "Mechanical properties and freeze-thaw durability of basalt fiber reactive powder concrete," Applied Sciences, vol. 10, no. 16, p. 5682, 2020.

[23] J. Nam, G. Kim, B. Lee, R. Hasegawa, and Y. Hama, "Frost resistance of polyvinyl alcohol fiber and polypropylene fiber reinforced cementitious composites under freeze thaw cycling," Composites Part B: Engineering, vol. 90, pp. 241-250, 2016.

[24] W. Zeng, Y. Ding, Y. Zhang, and F. Dehn, "Effect of steel fiber on the crack permeability evolution and crack surface topography of concrete subjected to freeze-thaw damage," Cement and Concrete Research, vol. 138, Article ID 106230, 2020.

[25] P. A. Claisse, Transport Properties of concrete Measurement and Applications, Elsevier, Amsterdam, Netherlands, 2014.

[26] C. Hall and W. D. Hoff, Water Transport in brick, Stone and concrete, CRC Press, Boca Raton, FL, USA, 2011.

[27] M. P. Kumar and P. Monteiro, Concrete: Microstructure, Properties, and Materials, McGraw-Hill Publishing, New york, NY, USA, 3rd edition, 2006.

[28] D. Li, S. Liu, and H. Liu, "Effect of capillary water absorption on electrical resistivity of concrete with coal gangue ceramsite as coarse aggregates," Advances in Civil Engineering, vol. 2021, Article ID 6623808, 12 pages, 2021.
[29] C. Hall, "Water sorptivity of mortars and concretes: a review," Magazine of Concrete Research, vol. 41, no. 147, pp. 51-61, 1989.

[30] F. H. Wittmann, A. D. A. Wittmann, and P. G. Wang, "Capillary absorption of integral water repellent and surface impregnated concrete," Restoration of Buildings and Monuments, vol. 20, no. 4, pp. 281-290, 2014.

[31] J. Bao, Z. Yu, L. Wang et al., "Application of ferronickel slag as fine aggregate in recycled aggregate concrete and the effects on transport properties," Journal of Cleaner Production, vol. 304, Article ID 127149, 2021.

[32] B. Liu, J. Shi, F. Zhou, S. Shen, Y. Ding, and J. Qin, "Effects of steam curing regimes on the capillary water absorption of concrete: prediction using multivariable regression models," Construction and Building Materials, vol. 256, Article ID 119426, 2020.

[33] M. Jamshidi, A. Jamshidi, N. Mehrdadi, and F. PachecoTorgal, "Mechanical performance and capillary water absorption of sewage sludge ash concrete (SSAC)," International Journal of Sustainable Engineering, vol. 5, no. 3, pp. 228-234, 2012.

[34] J. Bao, S. Li, P. Zhang, S. Xue, Y. Cui, and T. Zhao, "Influence of exposure environments and moisture content on water repellency of surface impregnation of cement-based materials," Journal of Materials Research and Technology, vol. 9, no. 6, pp. 12115-12125, 2020.

[35] A. Sarja and E. Vesikari, Durability Design of concrete Structures, CRC Press, Boca Raton, FL, USA, 2004.

[36] X. Li, S. Chen, Q. Xu, and Y. Xu, "Modeling capillary water absorption in concrete with discrete crack network," Journal of Materials in Civil Engineering, vol. 30, no. 1, Article ID 04017263, 2018.

[37] M. Alexander, A. Bentur, and S. Mindess, Durability of concrete: Design and Construction, CRC Press, Boca Raton, FL, USA, 2017.

[38] L. Wang and S. Li, "Capillary absorption of concrete after mechanical loading," Magazine of Concrete Research, vol. 66, no. 8 , pp. $420-431,2014$.

[39] J. Bao and L. Wang, "Effect of short-term sustained uniaxial loadings on water absorption of concrete," Journal of Materials in Civil Engineering, vol. 29, no. 3, Article ID 04016234, 2017.

[40] J. Bao, S. Li, Z. Yu et al., "Water transport in recycled aggregate concrete under sustained compressive loading: experimental investigation and mesoscale numerical modelling," Journal of Building Engineering, vol. 44, Article ID 103373, 2021.

[41] B. Van Belleghem, R. Montoya, J. Dewanckele et al., "Capillary water absorption in cracked and uncracked mortar - a comparison between experimental study and finite element analysis," Construction and Building Materials, vol. 110, pp. 154-162, 2016.

[42] X.-T. Chen, C. A. Davy, J. F. Shao, and F. Skoczylas, "Experimental and micro-mechanical analysis of the mechanical and transport properties of mortar containing heat-induced micro-cracks," Cement and Concrete Composites, vol. 32, no. 9, pp. 678-685, 2010.

[43] M. Pigeon, Durability of concrete in Cold Climates, CRC Press, Boca Raton, FL, USA, 2014.

[44] Z. Yang, W. J. Weiss, and J. Olek, "Water transport in concrete damaged by tensile loading and freeze-thaw cycling," Journal of Materials in Civil Engineering, vol. 18, no. 3, pp. 424-434, 2006. 
[45] J. Bao, S. Xue, P. Zhang, Z. Dai, and Y. Cui, "Coupled effects of sustained compressive loading and freeze-thaw cycles on water penetration into concrete," Structural Concrete, vol. 22, no. 4, pp. 1-11, 2020.

[46] Q. Gao, Z. Ma, J. Xiao, and F. Li, "Effects of imposed damage on the capillary water absorption of recycled aggregate concrete," Advances in Materials Science and Engineering, vol. 2018, Article ID 2890931, 12 pages, 2018.

[47] China Association for Engineering Construction Standardization (Cecs 13), Standard Test Methods for Fiber Reinforced concrete, China Planning Press, Beijing, China, 2009.

[48] National Standard of the People's Republic of China (Gb/T 50082), Standard for Test Methods of Long-Term Performance and Durability of Ordianry concrete, China Architecture \& Building Press, Beijing, China, 2009.

[49] Astm C1585, Standard Test Method for Measurement of Rate of Absorption of Water by Hydraulic-Cement Concretes, ASTM International, West Conshohocken, PA, USA, 2013.

[50] P. Zhang, F. H. Wittmann, M. Vogel, H. S. Müller, and T. Zhao, "Influence of freeze-thaw cycles on capillary absorption and chloride penetration into concrete," Cement and Concrete Research, vol. 100, pp. 60-67, 2017.

[51] Y. Wang, Y. Cao, P. Zhang et al., "Water absorption and chloride diffusivity of concrete under the coupling effect of uniaxial compressive load and freeze-thaw cycles," Construction and Building Materials, vol. 209, pp. 566-576, 2019.

[52] National Standards of the People's Republic of China (Gb/T 50081), Standard for Test Method of Mechanical Properties on Ordinary concrete, China Architecture \& Building Press, Beijing, China, 2002.

[53] Y. Ding, H. Liu, F. Pacheco-Torgal, and S. Jalali, "Experimental investigation on the mechanical behaviour of the fiber reinforced high-performance concrete tunnel segment," Composite Structures, vol. 93, no. 4, pp. 1284-1289, 2011.

[54] National Standards of the People's Republic of China (Gb/T 50476), Standard for Design of concrete Structure Durability, China Architecture \& Building Press, Beijing, China, 2019.

[55] D. Niu and Q. Xiao, "Analysis of cumulative damage characteristics and life prediction for the concrete in freezingthawing circumstance," Journal of Xi'an University of Architecture and Technology, vol. 2, no. 3, pp. 319-322, 2010.

[56] C. Meng, W. Li, L. Cai, X. Shi, and C. Jiang, "Experimental research on durability of high-performance synthetic fibers reinforced concrete: resistance to sulfate attack and freezingthawing," Construction and Building Materials, vol. 262, Article ID 120055, 2020.

[57] H. Li, M.-h. Zhang, and J.-p. Ou, "Flexural fatigue performance of concrete containing nano-particles for pavement," International Journal of Fatigue, vol. 29, no. 7, pp. 1292-1301, 2007.

[58] R. Sakin and İ. Ay, "Statistical analysis of bending fatigue life data using Weibull distribution in glass-fiber reinforced polyester composites," Materials \& Design, vol. 29, no. 6, pp. 1170-1181, 2008.

[59] Y. Ding, D. Li, Y. Zhang, and C. Azevedo, "Experimental investigation on the composite effect of steel rebars and macro fibers on the impact behavior of high performance selfcompacting concrete," Construction and Building Materials, vol. 136, pp. 495-505, 2017. 